\title{
Antibiotic Resistance Genes: Boon or Bane?
}

\author{
Rahul M Gami ${ }^{1}$ and Vivek M Patel ${ }^{2 *}$ \\ ${ }^{1}$ Mehsana Urban Institute of Science, Ganpat University, India \\ ${ }^{2}$ Taub Institute, Columbia University after Taub Institute, Staff Associate Officer of research, USA
}

*Corresponding author: Vivek M Patel, Staff Associate Officer of research, Taub Institute, USA.

To Cite This Article: Rahul M Gami, Vivek M Patel. Antibiotic Resistance Genes: Boon or Bane?. 2020 - 9(2). AJBSR.MS.ID.001373. DOI: 10.34297/ AJBSR.2020.09.001373.

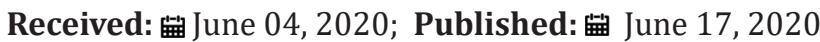

Keywords: ARG's; HGT; DNA Transformation; Environmental Contaminants; GMO's

Abbreviations: ARG's: Antibiotic Resistant Genes; HGT: Horizontal Gene Transfer; GMO: Genetically Modified Organism

\section{Introduction}

Bacteria are very dynamic organisms in nature and possesses exclusive ability to uptake foreign DNA and replicate them. This unique ability works in their favor to survive environmental changes and evolution. For instance, bacteria can uptake DNA that makes human insulin which can be useful to treat type I Diabetes. This very reason makes bacteria the most popular organism, that is widely used in research for amplifying desired gene and the process is called bacterial transformation. Bacterial transformation was first reported in 1928 by Griffith [1] in Streptococcus pneumoniae where some bacteria take up foreign genetic material from environment by horizontal gene transfer (HGT). In research labs the bacterial DNA (plasmid) can be used as a medium or vector to carry foreign DNA into a cell. The plasmid is mainly divided into 3 components, an origin of replication (specific sequence where DNA replication begins), a multiple cloning site (recognition sites for specific restriction enzymes to cut the plasmid and insert gene of interest) and a resistance gene (gene codes for a protein the bacteria need to survive in a selection growth medium).

\section{ARG's are powerful Tool in Biotechnology}

Antibiotic resistant genes (ARG's) are very popular tool in molecular biology and biotechnology. ARG's are widely used in bacterial transformation to get a higher yield of desired gene by eliminating the non-transformed bacteria under pressure of selection medium typically containing antibiotics. These ARG'S are harmless until the plasmids are stored safely in the freezers or disposed of properly. Once the plasmid is amplified and the DNA is purified the presence of ARG's in the plasmid is ignored.
Initial ignorance can be very costly mistake in the downstream process. These plasmids can be used in variety of fields (for instance agrobacterium in agriculture) to obtain genetically modified organisms (GMO's). Agro-GMO's are mainly grown to either enhance the herbicide effects (i.e. eliminate weeds without harming the crops) of crops [2], enhance insecticide effects of crops [3] or to enhance the yield and quality, to provide pest resistance against specific target insects [4].

\section{ARG's as Environmental Pollutants}

A study published in PNAS, 2013 [5] clearly shows that naturally occurring bacteria are more susceptible to take up short, fragmented or damaged DNA from their environment and can easily incorporate in their genome. Nature is in abundance of short and damaged DNA from centuries ago and we are adding more and more modified DNA to its library by introducing GMO's in fields moreover these forgotten ARG's are lethal biological threats silently contaminating environment at micro orgasmic level. There are evidences of HGT from host to parasite in flowering plant, from Parasite to host-insect, parasite to host-plants and even parasites to humans [6-9]. According to a study published in 2014, short and damaged DNA are easily taken up by human cells and integrated into human genome, moreover nucleic acids in food can enter blood stream and alter the gene expression in cells $[10,11]$. A study published in 2012, clearly demonstrates that synthetic plasmid vectors (ampicillin and beta-latam antibiotic resistance genes) are found in different proportion in six different rivers in china. They further made a shocking discovery, presence of third and fourth generation of cephalosporin drug resistant genes in transformants 
from Pearl and Haihe rivers [12]. There is a worldwide trend of ARG's contaminating water sources, plenty of microorganisms have develop resistance against broad range of antibiotics in all the sources of waste disposal such as medical waste, biohazard wastes, animal waste waters, sewage and waste water treatment plants furthermore they are also found in natural water such as underground water, surface water, drinking water $[13,14]$.

\section{ARG's are immortal threat to living Being}

ARG's are utilized to survive the selection pressure in the lab, on the contrary ARG's can evolve to survive the selection pressures of environment but they cannot be destroyed when the selection pressure is removed from the environment $[15,16]$. According to study published in Frontiers in Immunology, 2017 bacteria in the gut are most vulnerable to HGT of ARG's and other drug resistant genes from GMO food sources as Gut provides constant optimal conditions such as stable temperature, physicochemical conditions, constant nutrient supply (food we eat), extreme high concentration of microbial cells in the gut, foreign lethal DNA from GMO's and numerous chances of conjugation on the surface of gut tissue and food particles. These conditions make gut microflora most capable, dynamic, and easily transformable system to ARG's. [17]. A group of researchers have labelled Mammalian gut as "Melting Pot of Genetic Exchange" where there are highest chances of HGT occurrence [18].

\section{Conclusion}

ARG's being the most powerful tool for research should be used and disposed of responsibly within laboratory. These biological pollutants are immortal in nature and well known as 'easy-to-get, hard-to-lose just as any organic, heavy metal or plastic pollutants $[15,16]$. These ARG's were introduced in environment in the form of GMO's to get enhance yield, pest \& weed resistant properties in crops and over the period of years, these ARG's have been slowly incorporating in human genes. According to WHO (world health organization) the economic burden of antibiotic resistance on healthcare is being estimated up to $\$ 55$ Billion per year in the US and is estimated to increase up to $\$ 100$ Trillion by 2050. It is essential to conduct more studies and come up with innovative methodologies and technologies to replace use of ARG's and all other such resistance genes that end up in environment and cause more harm than good.

\section{Conflict of Interest}

There is no conflict of interest

\section{Reference}

1. Griffith F (1928) The Significance of Pneumococcal Types. J Hyg (Lond) 27(2): 113-159.

2. Devos Y, Cougnon M, Vergucht S, Bulcke R, Haesaert G, et al. (2008) Environmental impact of herbicide regimes used with genetically modified herbicide-resistant maize. Transgenic Res 17(6): 1059-1077.

3. Gatehouse A, Ferry N, Edwards M, Bell H (2011) Insect-resistant biotech crops and their impacts on beneficial arthropods. Philos Trans R Soc Lond B Biol Sci 366(1569): 1438-1452.

4. Pellegrino E, Bedini S, Nuti M, Ercoli L (2018) Impact of genetically engineered maize on agronomic, environmental and toxicological traits: a meta-analysis of 21 years of field data. Sci Rep 8(1): 3113.

5. Davis C, Wurdack K (2004) Host-to-Parasite Gene Transfer in Flowering Plants: Phylogenetic Evidence from Malpighiales. Sci 305(5684): 676678.

6. Overballe-Petersen S, Harms K, Oriando LA, Mayar JV, Rasmussen S, et al. (2013) Bacterial natural transformation by highly fragmented and damaged DNA. PNAS 110(49): 19860-19865.

7. Hotopp J, Clark M, Oliveira D, Foster J (2007) Widespread Lateral Gene Transfer from Intracellular Bacteria to Multicellular Eukaryotes. Sci 317(5845): 1753-1756.

8. Quispe-Huamanquispe D, Gheysen G, Kreuze J (2017) Horizontal Gene Transfer Contributes to Plant Evolution: The Case of Agrobacterium T-DNAs. Front Plant Sci 8: 1-6.

9. Bar D (2011) Evidence of Massive Horizontal Gene Transfer Between Humans and Plasmodium vivax. Nat Prec 5690: 1-17

10. Ho M (2014) Evolution by natural genetic engineering. Sci Soc 63: 1823.

11. Ho M (2014) Horizontal transfer of GM DNA why is almost no one looking? Open letter to Kaare Nielsen in his capacity as a member of the European Food Safety Authority GMO panel. Microb Ecol Health Dis 25: 25919.

12. Chen J, Jin M, Ziu ZG, Guo C, Chen ZL, et al. (2012) A survey of drug resistance blagenes originating from synthetic plasmid vectors in six Chinese Rivers. Environ Sci Technol 45(24): 344854.

13. Zhang X, Zhang T, Fang H. (2009) Antibiotic resistance genes in water environment. Appl Microbiol Biotechnol 82(3): 3970414.

14. Chee-Sanford JC, Aminov RI, Krapac IJ, Garrigues-Jeanjean N, Mackie RI (2001) Occurrence and diversity of tetracycline resistance genes in lagoons and groundwater underlying two swine production facilities. Appl Environ Microbiol 67(4): 1494-1502.

15. Aminov RI, Mackie RI (2007) Evolution and ecology of antibiotic resistance genes. FEMS Microbiol Lett 271(2):147-161

16. Salyers AA, Amabile-Cuevas CF (1997) Why are antibiotic resistance genes so resistant to elimination? Antimicrob Agents Chemother 41(11): 2321-2325.

17. Lerner A, Matthias T, Aminov R (2017) Potential effects of horizontal gene exchange in the human gut. Front Immunol 8: 1630.

18. Shterzer N, Mizrahi I (2015) The animal gut as a melting pot for horizontal gene transfer. Can J Microbiol 61(9): 603-605. 